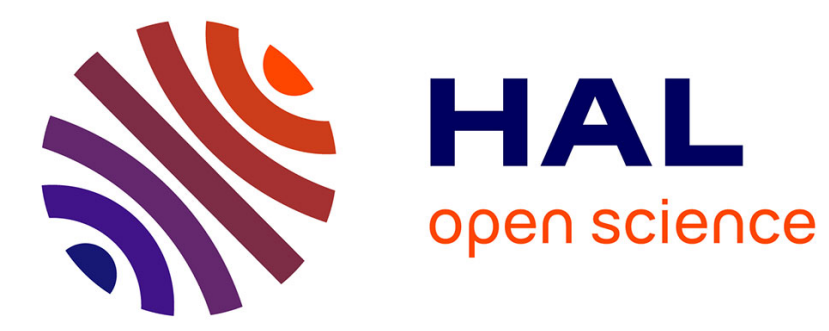

\title{
Evidence for a jacketed nematic polymer
}

\author{
F. Hardouin, S. Mery, M. Achard, Laurence Noirez, P. Keller
}

\section{To cite this version:}

F. Hardouin, S. Mery, M. Achard, Laurence Noirez, P. Keller. Evidence for a jacketed nematic polymer. Journal de Physique II, 1991, 1 (5), pp.511-520. 10.1051/jp2:1991185 . jpa-00247535

\section{HAL Id: jpa-00247535 https://hal.science/jpa-00247535}

Submitted on 1 Jan 1991

HAL is a multi-disciplinary open access archive for the deposit and dissemination of scientific research documents, whether they are published or not. The documents may come from teaching and research institutions in France or abroad, or from public or private research centers.
L'archive ouverte pluridisciplinaire HAL, est destinée au dépôt et à la diffusion de documents scientifiques de niveau recherche, publiés ou non, émanant des établissements d'enseignement et de recherche français ou étrangers, des laboratoires publics ou privés. 
Classification

Physics Abstracts

$6130-6225 \mathrm{H}-66.20$

\title{
Evidence for a jacketed nematic polymer
}

\author{
F. Hardouin ( $\left.{ }^{1}\right)$, S. Mery ( $\left.{ }^{1}\right)$, M. F Achard $\left({ }^{1}\right)$, L Norrez $\left({ }^{2}\right)$ and P Keller $\left({ }^{2}\right)$ \\ (1) Centre de Recherche Paul Pascal, Unıversité de Bordeaux I, av A Schweitzer, F-33600 \\ Pessac, France \\ (2) Laboratorre Léon Brilloun, CEA-CNRS/CEN Saclay, F-91191 Gif-sur-Yvette, France \\ (Recelved 5 November 1990, revised 21 January 1991, accepted 23 January 1991)
}

\begin{abstract}
Résumé. - Par des mesures de diffusion des neutrons aux petits angles nous montrons l'existence, pour un polysiloxane "en haltère ", d'une structure "chemsée » à l'échelle de l'organısatıon globale d'une chaîne en phase nématıque On constate que cette anısotropıe de forme du polymère a des conséquences sur l'évolution du coefficient de viscosité de torsion mesuré pour la première fors dans ce nouveau type de polymère à chaînes latérales

Abstract. - The evidence for a « jacketed "structure at the scale of the chain dimensions in the nematic phase of a "side-on fixed " liquid crystal polysiloxane is reported by using small angle neutron scattenng We relate this anisotropy of chain conformation to the first measurements of the rotational viscosity coefficient in this new type of liquid crystal side-chain polymer
\end{abstract}

\section{Introduction.}

« Side-on fixed " liquid crystal polymers form a new class of mesomorphic side chain polymers investigated in recent years In these compounds the mesogenic groups are laterally attached to the backbone through a flexible spacer (Fig. la) instead of a longitudinal connection ("side-end fixed") in the case of conventional hquid crystal side-chain polymers (Fig. 1b)

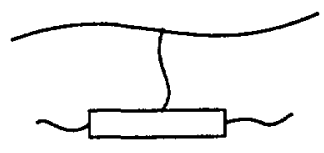

a

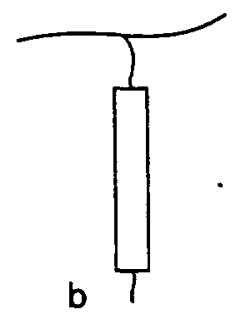

Fig 1 - Schematic representation of a) side-on fixed side-chain polymer and b) side-end fixed sidechain polymer 
Hessel and Finkelmann were the first to synthesize "side-on fixed " LCP composed of a polymethacrylate backbone and a p-phenylene dibenzoate type mesogenic morety [1]. Using similar mesomorphic side-groups, polyacrylates [2,3], polychloroacrylates [3] and polysiloxanes [4] have been reported subsequently. All these polymers were found to be purely nematic

We report here on small-angle neutron scattering (SANS) studies on a polysiloxane « $\mathrm{P}_{4,4,4}$ » (scheme 1), already studied by $\mathrm{X}$-ray analysıs [5], in order to establish the evolution with temperature of the global shape of the polymer from the isotropic to the nematic phase We will also try to relate this evolution of the shape of the polymer as a function of temperature with some results obtained on a typical property of the nematic phase, namely the rotational viscosity coefficient $\gamma_{1}$

\section{Study of the global conformation in the polysiloxane $\mathbf{P}_{\mathbf{4 , 4 , 4}}$.}

Referring to experiments in the case of conventional L C. side chain polymers [6] small-angle neutron scattering is a convenient method to explore this problem.

In practice we use a pseudo-binary system of fully protonated polymer $\left(\mathrm{P}_{4,4,4}\right)$ with the same polymer selectively deuterated on the aliphatic talls. As usual, a mixture of $50 / 50$ weight ratio is selected for a maximum scattered coherent intensity

Both polymers exhibit the same isotropic-nematic transition temperature and in the $50 / 50$ mixture we find that the biphasic region is rather sharp $\left(\sim 8^{\circ} \mathrm{C}\right)$.

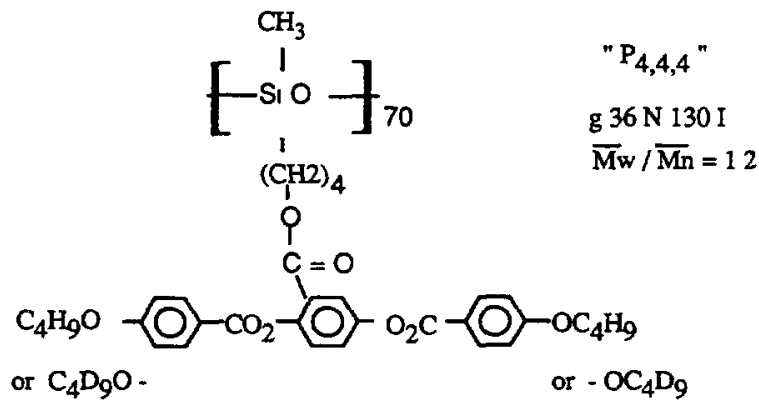

The experiments were performed with the spectrometer "PAXY" on the Orphée reactor of the Laboratoire Léon Brillouin (CEA/CNRS) in Saclay.

The sample was placed in the oven at a temperature regulated to $0.2^{\circ} \mathrm{C}$. A magnetic field of $1.4 \mathrm{~T}$ was applied to obtain a uniform onentation along the direction of the magnetic field in the nematic phase. The incident wavelength used was $\lambda=10 \AA$ and the distance between the detector and the sample was $2 \mathrm{~m}$. The range of scattering wave vector $q$ studied was $8 \times 10^{-3} \AA^{-1}<q<01 \AA^{-1}$. The scattering intensity $I(q)$ was obtained with a two-dimensional multidetector and the spectra were recorded in the $X Y$-plane perpendicular to the beam.

In the limit of small scattering wave vectors (Guinier range) the scattenng intensity $I(q)$ can be expressed as

$$
I^{-1}\left(q_{\|}\right)=I^{-1}(0)\left(1+q_{\|}^{2} R_{\|}^{2}\right) \quad q_{\|} R_{\Downarrow} \leqslant 1
$$

for a scattenng wave vector $q_{\|}$parallel to the magnetic field, where $R_{\|}$is the quadratic size of the macromolecule in the direction parallel to the magnetic field In the same way.

$$
I^{-1}\left(q_{\perp}\right)=I^{-1}(0)\left(1+q_{\perp}^{2} R_{\perp}^{2}\right) \quad q_{\perp} R_{\perp} \leqslant 1
$$


for a scattering wave vector $q_{\perp}$ perpendicular to the magnetic field, where $R_{\perp}$ is the quadratic size of the polymer in the direction perpendicular to the magnetic field.

Beside, in the isotropic phase we get

since

$$
\begin{gathered}
I^{-1}(q)=I^{-1}(0)\left(1+q^{2} \frac{R_{\mathrm{g}}^{2}}{3}\right) \\
R_{\|}=R_{\perp}=\frac{R_{\mathrm{g}}}{\sqrt{3}}
\end{gathered}
$$

where $R_{\mathrm{g}}$ is the radius of gyration of the whole molecule averaged over all directions

For instance in figure 2 the experimental values of

$$
I^{-1}\left(q_{1}\right)=f\left(q_{1}^{2}\right) \quad q_{\imath}=q_{\|} \text {or } q_{\perp}
$$

in the nematic phase $\left(70^{\circ} \mathrm{C}\right)$ are shown.

From the linearity in the range of

$$
q_{1} R_{l} \leqslant 1
$$

$R_{\|}$and $R_{\perp}$ can be deduced The error is estimated to be $5 \%-10 \%$.

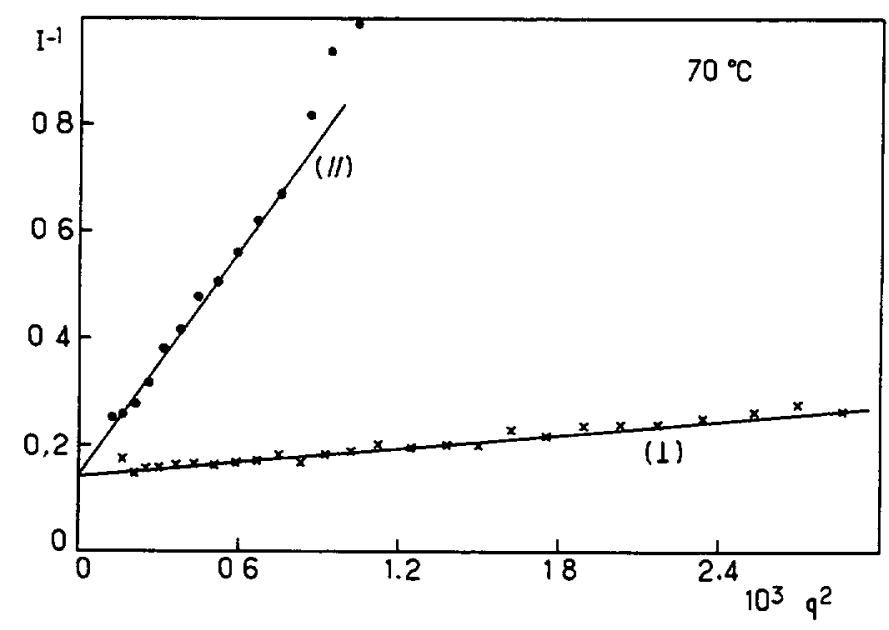

Fig. 2 - Inverse of the SANS intensity $I$ plotted in arbitrary units as a function of $q^{2}$ in the nematic phase $\left(T=70^{\circ} \mathrm{C}\right)$ For both direction $(\bullet)$ for $q_{\emptyset},(\times)$ for $q_{\perp}$, the straight lines are obtained from a least square method

The general features of the polymer dimensions are reported in figure 3 We see that, cooling down from the isotropic state, an anisotropy of the polymer shape appears in the nematic phase which increases with further cooling. Far enough from the I-N transition, a large extension of the dimension parallel to the magnetic field gives rise to a high value for the anisotropy $\left(R_{\|} / R_{\perp} \approx 4\right)$

This behaviour is very different from that encountered in the nematic phases of conventional LC side chain polymers In this case, whatever the nature of the backbone (polymethacrylate, polyacrylate, polysiloxane), the polymer exhibits small anisotropy which 


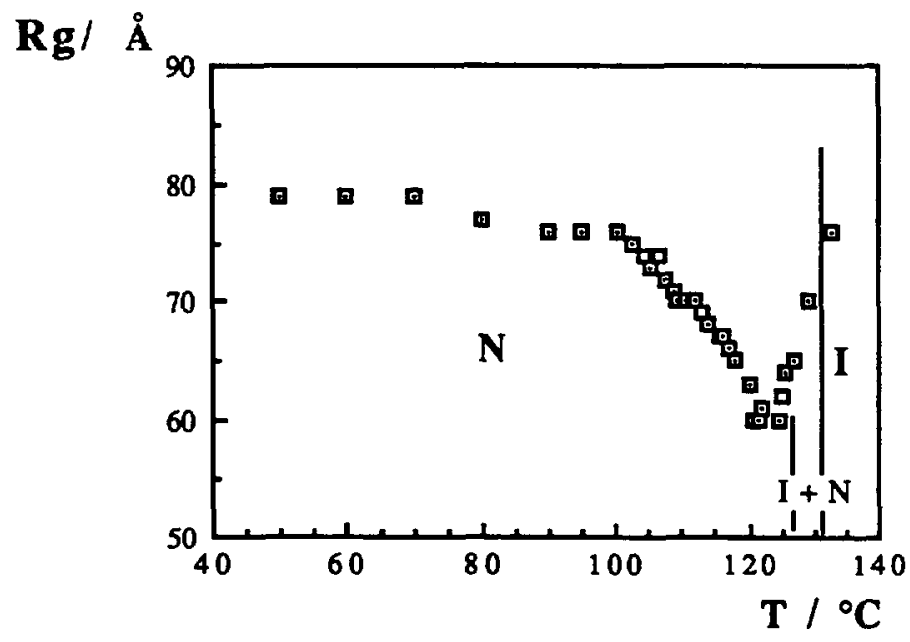

Fig 3 - Quadratic sizes in directions respectively parallel $\left(R_{\mathrm{f}}\right)$ and perpendicular $\left(R_{\perp}\right)$ to the magnetic field as a function of temperature $I$ isotropic liquid, $N$ nematic

is generally of oblate shape $\left(R_{1} / R_{\perp}<1\right)$ due to the strong tendency in comblike systems to give a smectic $A$ phase at lower temperatures [6-9]

On the other hand, as in the present case, a qualitatively and quantitatively similar prolate extension has been observed by D'Allest et al. [10] in main chain nematic polymers

A tentative description of the structural arrangement in the nematic phase of $P_{4,4,4}$ at low temperatures needs the integration of SANS measurements as well as X-ray (or neutron) diffraction at large $q$-values. Although flexible, the polysiloxane backbone is strongly streched in the average direction imposed by its mesogenic pendants (oriented on average along the magnetic field). Moreover the existence of $S_{\mathrm{c}}$ fluctuations revealed by $\mathrm{X}$-ray analysis on single domain [5] suggests inter- and intra-chain correlations between the mesogens (F1g 4)

Thus in agreement with the molecular argument of Q1-Feng Zhou et al. [2] we give evidence for the first time for a "jacketed" structure at the scale of the chain dimensions in the nematic phase of a «side-on fixed" polymer.

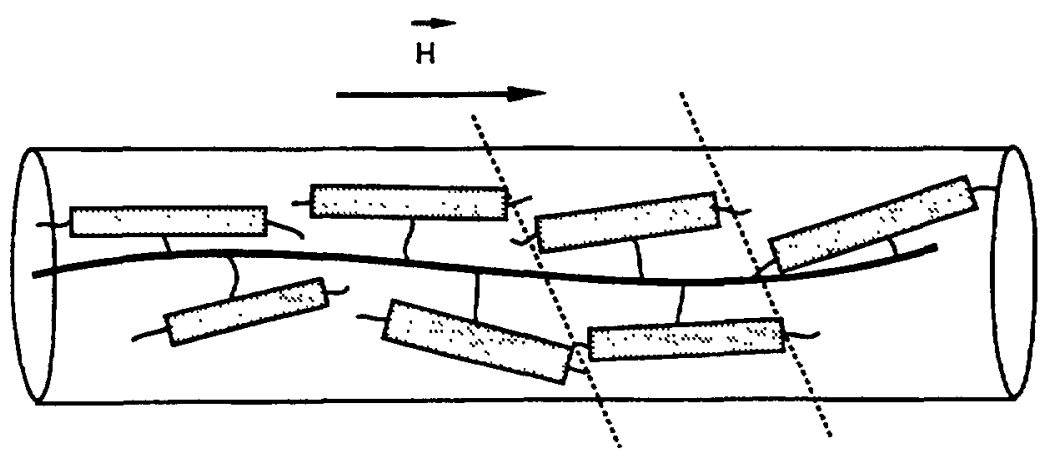

Fig 4 - Schematic representation of a nematic jacketed side-on fixed polysiloxane with $S_{c}$ local order 
3. Rotational viscosity $\gamma_{1}$ in the nematic phase of the polysiloxane « $P_{4,4,4}$ ».

Since the extension effect of the polymer is nearly saturated largely above the glassy state, one question can be raised. how is the viscosity for pure rotation of the director, $\gamma_{1}$, affected by varying the ratio $R_{\mathbb{l}} / R_{\perp}$ in the nematic phase? In order to study this dissipative property of the system [11] we have followed in real time the evolution of the relaxation angle $\theta-\varphi$ of the nematic director with the magnetic field after sudden finite rotation angle $\theta$ of the applied magnetic field (Fig. 5) Indeed the rotational viscosity coefficient $\gamma_{1}$ is thought to be large enough in the nematic polymer to maintain the director at $\varphi_{0}$ in the sample at the initial time $(t=0)$ following the sudden change in the magnetic field direction.

A rotating field method has been used $[12,13]$ in which the sample is placed in a cylindrical cell suspended by a quartz wire. The magnetic field created by an electro-magnet is allowed to rotate about the axis of suspension of the cell

The molecular reorientation process is described by a set of coupled equations

1) the local hydrodynamic equation of the Ericksen-Leslie-Parodi theory [14-16]

$$
\gamma_{1} \frac{\mathrm{d}(\varphi-\theta)}{\mathrm{d} t}=\frac{1}{2} \Delta \chi B^{2} \sin 2(\theta-\varphi)
$$

where

$B$ is the magnetic flux density and

$\Delta \chi$ is the anisotropy of the magnetic susceptibility per volume unit and

i1) the sum of the torques undergone by the system in viscous regime

$$
0=-C \alpha+V \gamma_{1}\left(\frac{\mathrm{d} \varphi}{\mathrm{d} t}-\frac{\mathrm{d} \alpha}{\mathrm{d} t}\right)
$$

where

$C$ is the twist constant of the quartz wire,

$V$ is the volume of the sample and

$\alpha$ is the rotation angle of the sample with respect to its equilibrium position without field.

For small values of the angle $\alpha$ (i.e. $\alpha \ll \alpha_{c}, \alpha_{c}$ critical angle connected to the maximum

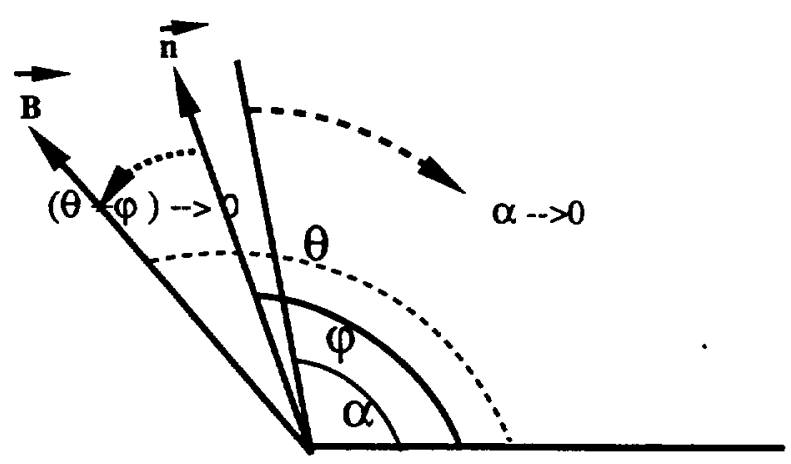

Fig 5 - Geometry corresponding to the determination of the rotational viscosity coefficient $\gamma_{1} \theta$ : constant angle of the applied magnetic field with the zero position $\varphi \cdot$ angle of the nematic director with the zero position $\alpha$ rotation angle of the cell with the zero position 
value $\theta-\varphi=\pi / 4$ ), equation (1) may be simplified by taking the approximation .

$$
\sin 2(\theta-\varphi) \approx 2(\theta-\varphi) \text {. }
$$

Solving equation (1) allows us to derive the characteristic time $\tau_{1}$.

$$
\gamma_{1} \frac{\mathrm{d}(\varphi-\theta)}{\mathrm{d} t} \approx \Delta \chi B^{2}(\theta-\varphi)
$$

then .

$$
(\theta-\varphi)=\text { Cte } \cdot \mathrm{e}^{-\frac{t}{\tau_{1}}}
$$

with :

$$
\tau_{1}=\frac{\gamma_{1}}{\Delta \chi \cdot B^{2}} \quad \text { and } \quad \text { Cte }=\left(\theta-\varphi_{0}\right)
$$

From equation (2), one gets a sum of two exponential terms which gives rise to $\tau_{1}$ and to a second characteristic time $\tau_{2}$ with $\tau_{2}=\mathrm{V} \gamma_{1} / C$ which describes the evolution of the rotation angle $\alpha$ versus time.

However in the limit of the experimental long time region, the plots Ln a versus $t$ are straight lines (Fig. 6), the relaxation of the cell to its initial position is governed by the following equation

$$
\alpha \approx \mathrm{e}^{-\frac{t}{\tau}}
$$

If we take into account the linear evolution of $\tau$ versus $1 / B^{2}\left(F_{1} g\right)$ :

$$
\tau \approx \tau_{1}=\frac{\gamma_{1}}{\Delta \chi \cdot B^{2}}
$$

Thus $\tau_{1}$ is predominant in the limit of small values of $B(B<1.1 \mathrm{~T})$

\section{$\log \alpha$}

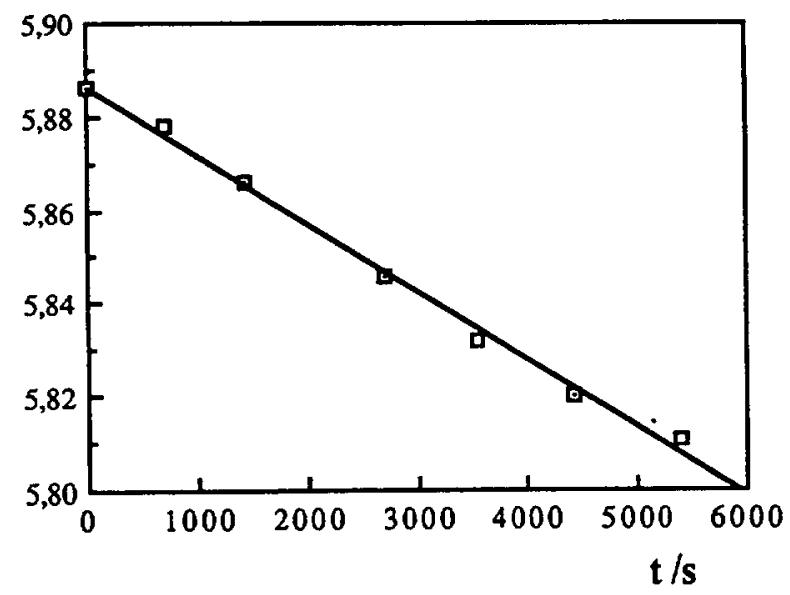

Fig 6 - Example of the evolution of the logarithm of the rotation angle $\alpha$ of the cell with the zero position 


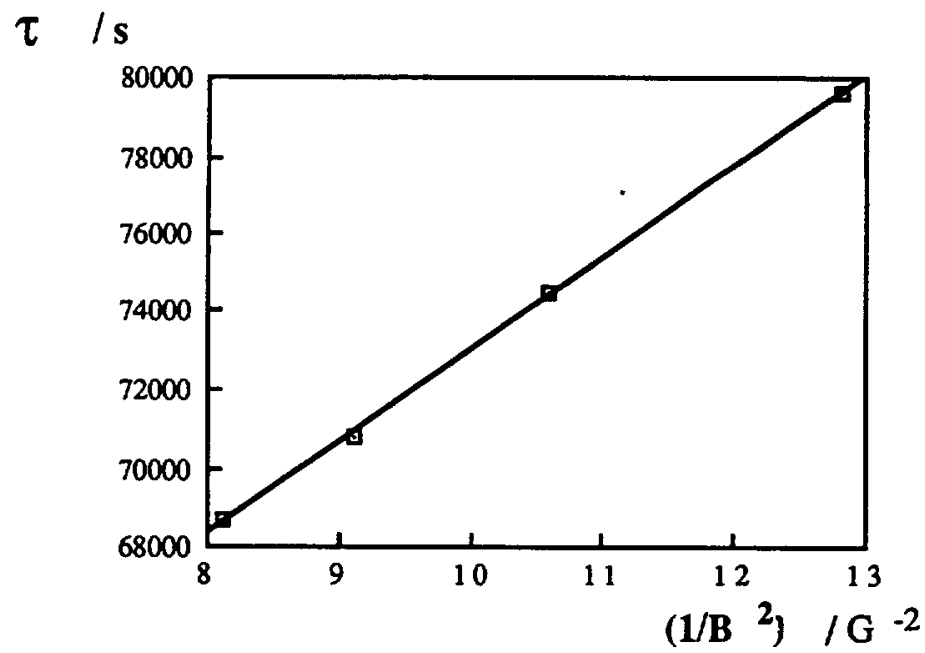

Fig 7. - Example of the evolution of the characteristic time $\tau$ as a function of $1 / B^{2}$, where $B$ is the magnetic flux density

A measure of the slope of the straight line $\tau=f\left(1 / B^{2}\right)$ therefore gives the ratio $\gamma_{1} / \Delta \chi$. Using the magnetic susceptibility and density data previously reported for the "sideon fixed 》 polysiloxanes [5] it is possible to deduce the value of $\gamma_{1}$ for each temperature investigated.

In spite of the fact that each evaluation of $\tau$ requires large duration (as long as several hours), we have estımated the temperature dependence of $\gamma_{1}$ over the interval corresponding to a significant evolution of the polymer shape In figure 8, experimental values of $\gamma_{1}$ as a function of the reduced temperature are presented It appears that the rotational viscosity grows rapidly as the polymer becomes longer. The anisotropy dependence of the viscosity is illustrated in figure 9 This result is in qualitatively good agreement with recent measurements reported in solutions of a main-chain polymer nematic liquid crystal [18].

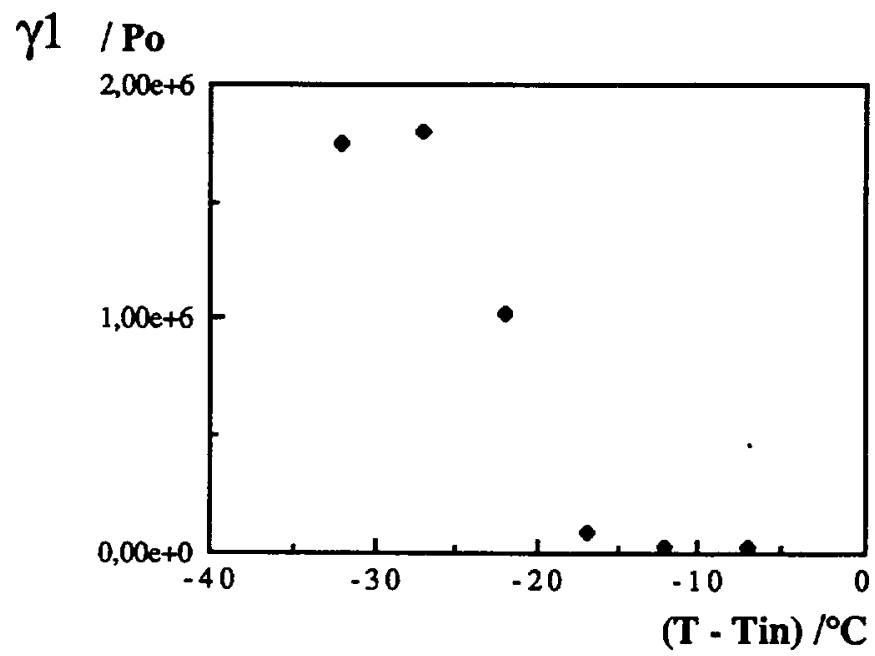

Fig 8 - Thermal dependence of the rotational viscosity coefficient $\gamma_{1}$ in the nematic phase 


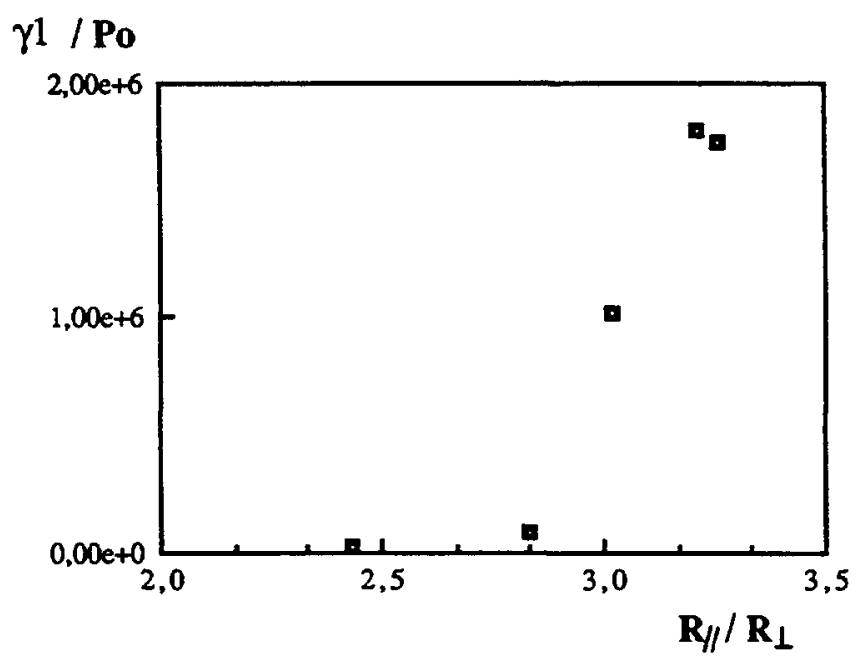

Fig 9 - Evolution in the nematic phase of the rotational viscosity coefficient $\gamma_{1}$ as a function of the ratio $R_{\mid} / R_{\perp}$ of the quadratic sizes in directions parallel $\left(R_{\|}\right)$and perpendicular $\left(R_{\perp}\right)$ to the magnetic field.

Relating the molecular aspect and the macroscopic properties the exaltation of the viscosity $\gamma_{1}$ appears essentially as a consequence of the thermal evolution of the chain extension in this "side-on fixed" polysiloxane nematic liquid crystals This is in qualitative agreement with Brochard's calculation in the case of stick-like behaviour [19].

Here, the first step from the isotropic phase to the nematic phase leads to a shrink the dimension of the polymer in the direction perpendicular to the director $\left(R_{\perp}\right)$ due to the localization of the labelling and to the spontaneous onentation of the mesogenic groups along the magnetic field. $R_{\|}$is hence weakly modified since the excluded volume is large enough. Thus, as shown in figure $8, \gamma_{1}$ presents a regular evolution near $T_{\mathrm{NI}}$. Then, with decreasing temperature, the mesogenic interactions are strengthened and they play an important role in the extension of the polymer. For $R_{\|}$a rapid increase to saturation is observed while $R_{\perp}$ remains rather constant. Thus in this final step, $\gamma_{1}$ becomes extremely large.

Comparing the orders of magnitudes, the values for $\gamma_{1}$ of this « side-on fixed » polysiloxane are two or three decades higher than the ones of comparable L.C. " side-end fixed " polymers [20-23] Therefore (with equivalent molecular weight and mesogenic group at the same reduced temperature and with similar nematic order parameter) the apparent activation energy is expected to be larger for the "side-on fixed" polymers Preliminary dynamic dielectric relaxation measurements [24] emphasized this difference between these two types of $\mathrm{L} C$ side chain polymers

Finally, the increase in $\gamma_{1}$ in the "side-on 》 as compared to the "side-end " polysiloxanes is probably due to a larger anisotropy as well as larger friction coefficients

\section{Concluding remarks.}

In the light of the results presented, we can look at the thermal evolution of the average radius of gyration $R_{\mathrm{g}}$ in the nematic range:

$$
R_{\mathrm{g}}=\sqrt{R_{\mathbb{l}}^{2}+2 R_{\perp}^{2}}
$$




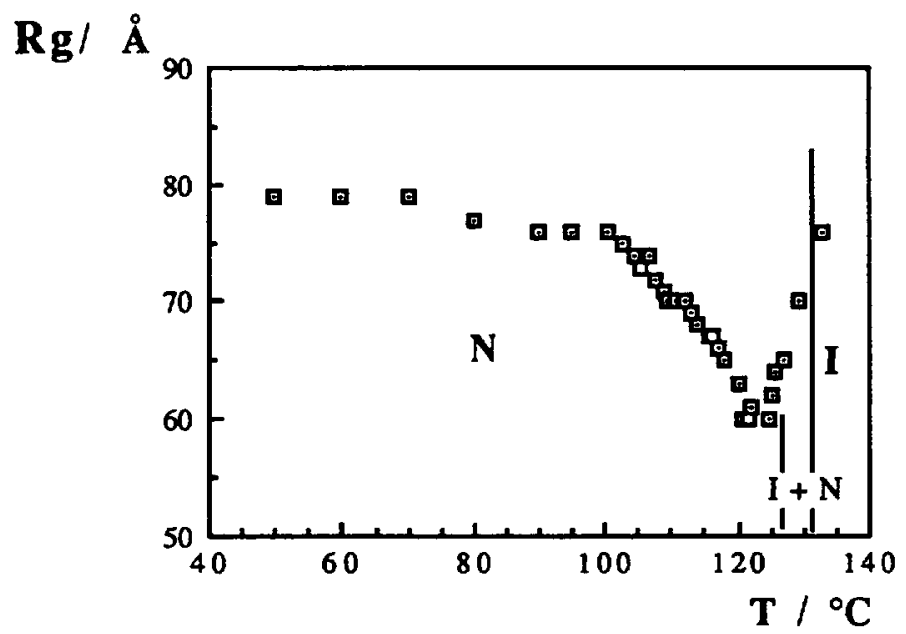

F1g 10 - Thermal evolution of the average radius of gyration $R_{\mathrm{g}}$ in the nematic range

Figure 10 shows a minimum of $R_{\mathrm{g}}$ located in an intermediate stage where the macroscopic magnetic anısotropy also exhibits an unusual minimum [5]. These striking results observed in $P_{4,4,4}$ raise the general question of the significant role played by the mechanisms of the chain extension in the establishment of the orientational order of polymer nematics. In addition, the existence of a non-regular dependence on temperature of the average radius of gyration should affect other static and dynamic physical properties in the nematic state

\section{Acknowledgments.}

Thanks are expressed to Dr J Prost and Dr J P Marcerou for helpful discussions and assistance in data analysis of the viscosity studies

\section{References}

[1] Hessel F., Finkelmann H, Polym. Bull 14 (1985) 375

[2] QI-Feng Zhou, Hui-Min, XI-De Feng, Macromolecules 20 (1987) 233, Mol Cryst Liq. Cryst 155 (1988) 73

[3] Hessel F., Finkelmann H , Makromol Chem 189 (1988) 2275

[4] Keller P, Hardouin F, Mauzac M, Achard M F, Mol Cryst. Liq Cryst 155 (1988) 171

[5] Hardouin F., Mery S, Achard M F, Mauzac M, Davidson P, Keller P, Liq. Cryst 8 (1990) 565

[6] NoIrez L, Thesıs, Saclay, Université Paris-Sud (1989)

[7] Keller P., Carvalho B, Cotton J P, Lambert M, Moussa F., Pépy G, J Phys Lett 46 (1965) L 1065

[8] Moussa F, Cotton J P, hardouin F., Keller P, Lambert M, Pépy G, Mauzac M, RICHARD H., $J$ Phys France 48 (1987) 1079.

[9] Hardouin F, Notrez L, Keller P, Lambert M., Moussa F, Pépy G, Mol Cryst Liq Cryst. 155 (1988) 389

[10] D’Allest J. F., Maissa P, Ten Bosch P, Sixou P, Blumstein A., Blumstein R., Teixeira J, NoIrez L, Phys Rev Lett. 61 (1988) 2562 
[11] DE GenNes P G., a) The Physics of Liquid Crystals (Clarendon Press) 1974 ; b) Polymer Liquid

Crystals · Ciferm A., Krigbaum N R., Meyer R. B Eds (Academic Press) (1982) 115

[12] Prost J., Gasparoux H., Phys. Lett 36A (1971) 245

[13] Gasparoux H., Prost J., $J$ Phys France 32 (1971) 953

[14] LesLie F. M., Archs ration Mech Analysis 228 (1968) 265.

[15] ERICKSEN J L., Phys. Fluids 9 (1966) 1205.

[16] Parodi O., $J$ Phys France 31 (1970) 581

[17] Hardouin F, Achard M F., Gasparoux H, Sold State Commun. 14 (1974) 453

[18] Sin-Doo Lee, Meyer R B, Phys. Rev. Lett 61 (1988) 2217; Liq Cryst 7 (1990) 15

[19] Brochard F, J. Pol Sci. 17 (1979) 1367.

[20] Fabre P., Casagrande C., Veyssié M, Finkelmann H., Phys Rev Lett 53 (1984) 993

[21] Casquilho J. P., Volino F., Mol Cryst Liq Cryst 180B (1990) 357

[22] Van der Putten D, Schwenk N., Spiess H W, Liq Cryst. 4 (1989) 341

[23] Rupp W, GrossmanN H. P, Stoll B., Liq Cryst 3 (1988) 583.

[24] Bormuth F J., HaAse W, Liq. Cryst 3 (1988) 881. 